\title{
O PENHOR RURAL COMO GARANTIA NOS CONTRATOS DE ARRENDAMENTO RURAL
}

Priscila Dibi Schvarcz ${ }^{1}$

Sumário: 1. Direitos reais de garantia. 2. Penhor. 3. Penhor rural. 4. Penhor rural como garantia nos contratos de arrendamento rural

PALAVRAS-CHAVE: PENHOR - PENHOR RURAL - ARRENDAMENTO RURAL DIREITOS REAIS DE GARANTIA.

\section{INTRODUÇÃO}

O Direito Agrário, como ramo da ciência jurídica, é de estudo recente no Brasil. A União passou a ter competência para legislar sobre a matéria a partir da Emenda Constitucional no. 10 de 10.11.1964. Em 30.11.1964 foi promulgada a Lei no. 4504, o Estatuto da Terra, que recebeu regulamentação pelo Decreto 59.566, de 14.11.1966.

O Estatuto da Terra trouxe uma idéia radical de mudança na estrutura do campo. Abandonou-se o sistema que vigorava, em que as relações advindas do campo eram reguladas pelas normas de direito civil, as quais embasavam-se na liberdade contratual, para a adoção de um diploma nitidamente protetivo tanto em relação ao trabalhador rural, quanto à preservação dos recursos naturais e racional exploração da terra.

Dessa maneira, através da análise das normas do Estatuto da Terra, tem-se um 'contrato base', ou seja, as partes têm liberdade de pactuar acerca de matéria não nele disposta, sem todavia contrariarem os princípios gerais por ele instituídos.

Com base nisso e diante da não previsão de institutos para garantirem o pagamento do aluguel, no arrendamento rural _ como o faz a Lei de Locações Urbanas (Lei nํ. 8245/91), em seu art 37_, se dispõem o presente artigo a

\footnotetext{
${ }^{1}$ Advogada no Rio Grande do Sul. Pós-graduanda em direito constitucional pela UNISUL/IELF. Professora substituta da Universidade Federal de Santa Maria - UFSM.

(C) 2008. Departamento de Direito da UFSM. Todos os direitos reservados.
} 
trazer uma alternativa aos arrendadores e arrendatários no que tange a inserção de cláusula prevendo garantia ao pagamento do aluguel no contrato de arrendamento rural. Isso se faria através da celebração de contrato de penhor rural, penhor esse que viria a garantir o recebimento do valor referente ao aluguel por parte do arrendador em caso de inadimplência do arrendatário.

O recebimento do valor referente ao aluguel ocorreria através de venda judicial ou amigável, esta última se prevista no contrato, dos bens dados em garantia, ou seja, dos bens empenhados. A possibilidade de venda decorre do direito que possui o credor pignoratício, o denominado direito de excussão.

\section{Direitos reais de garantia}

Os direitos reais de garantia constituem reminiscências da vinculação física e moral das pessoas e bens ao poder de disposição do credor.

Com efeito, na civilização egípcia, o devedor recalcitrante tinha sua própria pessoa adjudicada ao credor. Os hebreus adonavam-se do devedor, de sua mulher e de seus filhos, que se transformavam em escravos. Mesmo em Roma, civilização com grau maior de cultura jurídica, permitia-se o encarceramento do inadimplente, e inclusive leiloá-lo em feiras de escravos. Fixava a Lei das XII Tábuas, na Tábua III: "Tertiis nundinis partis secanto. Si plus minuesve secuerunti, se fraude esto". Vale dizer que o devedor respondia com o próprio corpo, sobre o que incidia o poder do credor. Somente no ano 326 a.C., com a Lex Poetelia Papira, foi abolida a execução contra a pessoa do devedor, instituindo-se a responsabilidade sobre seus bens, se a dívida não procedesse de delito.

A execução sobre os bens do devedor constitui, pois, garantia para o credor. Assim, pelos débitos assumidos voluntariamente ou decorrentes de lei, respondem os bens do devedor, tomando o vocábulo "bens" em sentido genérico, abrangentes de todos os valores ativos de que seja titular.

Atendendo à natureza especial de certas obrigações, a lei confere privilégios ao credor, com a faculdade de receber prioritariamente. São eles: custas judiciais, impostos e taxas devidos à Fazenda Pública, salários e indenizações trabalhistas, indenizações por acidentes no trabalho, etc. 
A par dos privilégios nascidos do mandamento legal, admite-se, por força de convenção, que a dívida se revista de segurança especial. A esta segurança dá-se o nome de garantia, no sentido de que proporciona ao credor condições privilegiadas de recebimento.

A garantia pode ser: I) pessoal ou fidejussória, consistindo em que uma pessoa estranha à relação principal se responsabilize pela solução da dívida (fiança e aval); ou II) real, mais eficaz do que as garantias pessoais, quando se vincula ao pagamento um determinado bem do devedor (penhor, hipoteca e anticrese).

Três atributos preponderam nos direitos reais de garantia: a seqüela, a preferência e a acessoriedade.

Pela seqüela, o vínculo real que une a coisa dada em garantia com a dívida garantida, se impregna de tal forma no bem que o segue onde for e com quem estiver. Assim, o direito de disposição não é limitado pelo gravame, pois este acompanhará o bem enquanto não extinta a obrigação principal.

Pela preferência ou prelação, o gravame garante que o crédito do titular da garantia seja satisfeito preferencialmente aos demais, respeitados os créditos especiais, também conhecidos como privilégios.

Para tanto, deve o gravame ser registrado no ofício imobiliário, somente assim, será oponível a terceiros, ou seja, somente assim, surgirá a preferência.

De ressaltar, ainda, a acessoriedade. Os direitos de garantia não subsistem por si. Extinta a dívida, desaparecem ipso facto, cessando sua existência.

O efeito básico, portanto, das garantias reais reside em separar do patrimônio um bem que era ali a segurança comum a todos os credores, e afetá-lo ao pagamento prioritário de determinada obrigação.

\section{Penhor}


A palavra penhor tem mais de um sentido na lei. "Ora se chama penhor a) o negócio jurídico de penhor, ora b) o direito real que desse negócio jurídico se irradia, ora c) a própria coisa empenhada".2

Constitui-se o penhor com a efetiva transmissão da posse direta, ou tradição, de um bem móvel, das mãos do devedor, ou de terceiro anuente, de quem tem titularidade dominical, para as mãos do credor, ou de quem o represente, com a finalidade de, criando um vínculo real entre o móvel e a dívida do devedor para com o credor, garantir a satisfação do débito. ${ }^{3}$

O penhor tem como características: a) acessoriedade: não tem autonomia para existir sem uma dívida à qual garanta; b) indivisibilidade: o vínculo real que garante a dívida se insere em todas as partículas da coisa, ou coisas, dadas em penhor. Não há, por isso, uma relação dependente entre o valor da coisa, ou coisas, dadas em garantia e o valor da dívida, ou obrigação, que importe, a cada amortização desta, a exoneração automática e proporcional do valor da coisa, ou coisas. Não se trata, todavia, de princípio cogente, podendo haver estipulação em contrário; c) temporariedade: o penhor não é perpétuo, tal temporariedade se prende ao próprio fato da dívida ser temporária; d) extensibilidade: as acessões e acessórios, já existentes no momento da constituição do penhor, estão integrados na garantia real. Os supervenientes à constituição da garantia real, se inserem em tal garantia.

Constitui-se o penhor por ato negocial inter vivos, ou seja, pela convenção bilateral, o denominado contrato. Tal convenção deve ter um conteúdo mínimo para valer contra todos: total da dívida garantida, ou sua estimação ou valor máximo; fixação do prazo para pagamento; taxa de juros, se houver; e a especialização da coisa dada em garantia, bem individuada e identificada. Identicamente, há a constituição por ato de última vontade, causa mortis.

Assim, constitui-se o penhor para garantir um débito ou uma dívida. Para tanto, exige-se a efetiva transmissão da posse do bem. Essa tradição essencial ao penhor, no entanto, não tem o efeito de transmitir a propriedade, mas a posse, o

\footnotetext{
${ }^{2}$ PONTES DE MIRANDA, Franscico Cavalcanti. Tratado de Direito Privado. 3. ed. Tomo XX. Ed. Revista dos Tribunais, Rio de Janeiro, 1983. p. 393

${ }^{3}$ NASCIMENTO, Tupinambá Miguel Castro do. Penhor e Anticrese. Ed. Aide, Rio de Janeiro, 1986.
}

(C) 2008. Departamento de Direito da UFSM. Todos os direitos reservados. 
contato físico com a coisa. Tem-se, portanto, que o penhor é um direito real mobiliário.

"O direito de penhor é direito real de realização do valor do bem

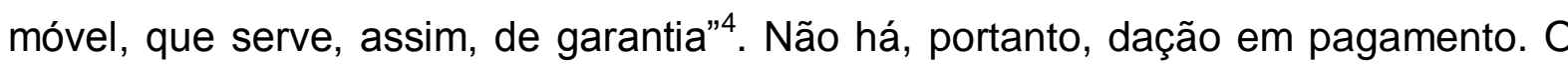
que há é realização do valor do bem empenhado, através de venda, e com o valor apurado se satisfazer a dívida, ou a obrigação transformada em perdas e danos. A esta realização se chega através do direito que se concede ao credor pignoratício, denominado de direito de excussão ${ }^{5}$.

\section{Penhor rural}

O penhor rural constitui uma forma especial de penhor. Possui contornos específicos e traços diferenciadores do penhor tradicional.

Os principais elementos de especificação do penhor rural são: I - a desnecessidade de tradição; II - a inscrição no registro de imóveis da circunscrição imobiliária a que estiver afeto o imóvel onde se encontre a coisa empenhada; III prazo limitado de três ou quatro anos, prorrogáveis uma só vez por período igual de tempo; IV - o objeto ${ }^{6}$ sobre que pode recair o penhor, que, segundo alguns autores, podem ser até bens imóveis por destinação, devendo ser especificado com o máximo de precisão para poder a coisa ser identificada. Ainda podem ser objeto do penhor rural safras pendentes, em formação ou futuras, o que constitui uma diferença substancial em relação ao penhor ordinário; V - o penhor rural deu origem à Cédula Rural Pignoratícia, com o advento da Lei 492/37, baseada na transcrição do penhor no registro imobiliário, ocasião em que poderia o oficial do registro expedir a cédula rural a pedido do credor (art. 15 da Lei 492), a qual poderia circular mediante endosso.

\footnotetext{
${ }^{4}$ PONTES DE MIRANDA, Franscico Cavalcanti. Tratado de Direito Privado. 3. ed. Tomo XX. Ed. Revista dos Tribunais, Rio de Janeiro, 1983. p. 394.

${ }^{5}$ Direito de excussão é o direito que tem o credor pignoratício de, ante o inadimplemento do devedor quanto à satisfação da dívida, ou da obrigação, através de sua venda judicial ou amigável, nesta última hipótese se o permitir o contrato ou houver procuração especial do devedor, autorizando. Não se inclui nesse direito, a faculdade do credor se tornar dono do bem empenhado. Tal cláusula, denominada pacto comissório, é vedada por lei.

${ }^{6}$ Art 1442: "Podem ser objeto de penhor: I - máquinas e instrumentos de agricultura; II - colheitas pendentes ou em via de formação; III - frutos acondicionados ou armazenados; IV - lenha cortada e carvão vegetal; V animais do serviço ordinário de estabelecimento agrícola.

Art 1444: Podem ser objeto de penhor os animais que integram a atividade pastoril, agrícola ou de laticínios”.
}

(C) 2008. Departamento de Direito da UFSM. Todos os direitos reservados. 
O penhor rural é, por isso, um importante instrumento para fomento da produção agrária, na medida em que facilita a captação de créditos no setor agrícola e pecuário.

No dizer de Carvalho Santos, o penhor rural "visa facilitar a circulação da riqueza representada pelos frutos, favorecendo assim o crédito agrícola e o desenvolvimento da agricultura, pois permite ao agricultor que o seu trabalho represente capital, ainda antes da colheita". ${ }^{7}$ Além disso, de que valeria ao agricultor ou pecuarista tomar empréstimos sobre os instrumentos agrários ou gado leiteiro, se o financiamento lhe impusesse desprover a lavoura ou o plantel dos elementos geradores de recursos?

Assim, não há mais lugar, na atualidade do direito pátrio, para a resistência, que antes se levantava, contra os penhores especiais, sob o fundamento de que desvirtuavam a natureza essencial dessa garantia ao abrangerem bens imóveis por acessão ou transigirem com o conceito clássico da imissão do credor na posse do objeto. Chegava-se ao ponto de serem nominados, o penhor rural e industrial, como hipoteca mobiliária ou hipoteca móvel, ou seja, serem considerados formas intermediárias aos contratos de penhor e hipoteca.

De ressaltar, ainda, que o penhor rural divide-se em dois tipos: penhor agrícola e penhor pecuário. Em quaisquer deles a obrigação principal deve necessariamente estar voltada à atividade rural.

\section{Penhor rural como garantia nos contratos de arrendamento rural}

O Direito Agrário, como ramo da ciência jurídica, é de estudo recente no Brasil. A União passou a ter competência para legislar sobre a matéria a partir da Emenda Constitucional no. 10 de 10.11.1964. Em 30.11.1964 foi promulgada a Lei nํ. 4504, o Estatuto da Terra, que recebeu regulamentação pelo Decreto 59.566, de 14.11.1966.

Tal Estatuto tem contornos nitidamente sociais, pois seus dispositivos, de modo sistemático, visam, não somente, proteger o homem do

\footnotetext{
7 SANTOS, J.M. de Carvalho. Código Civil Interpretado. Direito das Coisas. 12. ed. vol. X. Ed. Freitas Bastos, Rio de Janeiro, 1982.
} 
campo em detrimento do proprietário rural, mas também, a própria terra, os recursos naturais. Esse caráter protetivo ressalta em diversos pontos, como no informalismo, prazos mínimos, cláusulas obrigatórias, direito de preferência, dentre outros.

Nas palavras de Wellington Pacheco Barros ${ }^{8}$ :

"De um autonomismo de vontade, como é a estrutura do Código Civil, passou-se para um dirigismo estatal nitidamente protetivo, como se revestem todos os dispositivos do direito agrário. Em outras palavras, afastou-se o sistema de liberdade de ação das partes envolvidas em qualquer questão agrária, para uma forte e coercitiva tutela estatal de proteção absolutamente favorável ao trabalhador rural, num claro reconhecimento da existência de desigualdades no campo a merecer intervenção desigual do Estado legislador".

E, ainda, segundo José Fernando Lutz Coelho ${ }^{9}$ :

"O Direito Agrário (...) tem como preocupação fundamental a conservação da terra visando a uma maior diversificação e a um máximo aproveitamento da produção natural, o que sói acontecer se houver um uso múltiplo e integrado, bem como mantendo-se a estrutura e destinação da terra e respeitando-se a fauna, flora e demais elementos naturais, de forma a promover o equilíbrio ecológico necessário ao melhor aproveitamento do solo".

Dessa maneira, cumpre dizer que existe, no Direito Agrário, a liberdade de contratar característica do direito privado, no entanto, tal liberdade é relativizada, uma vez que são irrenunciáveis os direitos e vantagens definidos em lei, ou seja, a liberdade contratual, em sede de Direito Agrário, não é plena.

Assim, não podem as partes renunciar a direitos que a lei assegura, no entanto podem estipular livremente cláusulas que não contrariem o disposto no Estatuto da Terra.

O Estatuto da Terra não faz qualquer referência à possibilidade de fixação de garantia para pagamento do aluguel em caso de inadimplemento do arrendatário. Além disso, segundo o art. 88 do Decreto 59.566/66: "No que forem

\footnotetext{
8 BARROS, Wellington Pacheco. Curso de Direito Agrário. 3. ed., vol. I. Ed. Livraria do Advogado, Porto Alegre, 1998. p. 29.

9 COELHO, José Fernando Lutz. Contratos Agrários de Arrendamento e Parceria Rural no Mercosul. Ed. Juruá, Curitiba, 2002. p. 38.
}

(C) 2008. Departamento de Direito da UFSM. Todos os direitos reservados. 
omissas as Leis nº. 4504/64, 4947/66 e o presente Regulamento, aplicar-se-ão as disposições do Código Civil, no que couber".

Podem, portanto, as partes fazerem uso, analogicamente, das garantias previstas na Lei no. 8245/91, Lei de Locações Urbanas, ou seja, caução e fiança (o seguro de fiança locatícia somente pode ser usado para o caso de locação urbana). As possibilidades de fixação de garantia não ficam aí restritas.

Podem, ainda, as partes celebrar um contrato de penhor rural, de modo que o maquinário, os animais, a safra, etc. possam garantir o pagamento do aluguel em caso de inadimplemento. Tal alternativa não é utilizada costumeiramente, no entanto, plenamente viável, uma vez que não há qualquer impedimento em utilizar-se do penhor rural nesses casos.

Os pressupostos para sua utilização estariam satisfeitos, pois a obrigação principal estaria voltada à atividade agrária, os bens empenhados, igualmente, poderiam continuar na posse do empenhante-arrendatário, de modo a não subtrair-lhe os instrumentos necessários à sua produção. Em contrapartida, estaria o proprietário da terra munido do privilégio de receber seu crédito prioritariamente aos demais credores, em caso de inadimplemento e eventual insolvência do arrendatário.

Não há, portanto, qualquer impedimento à utilização do penhor rural como garantia do pagamento do aluguel em um contrato de arrendamento rural, uma vez que constitui-se o penhor para garantir um débito, uma dívida, quaisquer que sejam eles.

"A lei falando em débito, parece fazer crer que só admite o penhor quando a causa originária da obrigação for o mútuo, quando, na realidade, assim não é. O que se exige é uma obrigação principal a ser garantida pelo penhor. Em outros termos, a dívida pode ser pecuniária, representada por um valor monetário específico, como pode ser uma obrigação de fazer ou não fazer, cujo inadimplemento é reparado monetariamente, através de perdas e danos". ${ }^{10}$

O penhor rural, no entanto, é raramente utilizado em outra hipótese que não o crédito rural. Diz o art. $2^{\circ}$ da Lei nํ. 4829/65:

${ }^{10}$ NASCIMENTO, Tupinambá Miguel Castro do. Penhor e Anticrese. Ed. Aide, Rio de Janeiro, 1986. 
"Considera-se crédito rural o suprimento de recursos financeiros por entidades públicas e estabelecimento de crédito particulares a produtores rurais ou suas cooperativas para aplicação exclusiva em atividade que se enquadrem nos objetivos indicados na legislação em vigor".

Do conceito legal, evidencia-se que o crédito rural é dinheiro oficial, ou particular especialmente vinculado, que o governo destina de forma subsidiada ao produtor rural ou às suas cooperativas, ou seja, é contrato que tem como objeto empréstimo de dinheiro para o desenvolvimento do campo. Tal contrato se insere na categoria de contrato oneroso e quase absolutamente vem protegido com garantias reais ou pessoais. A garantia mais utilizada no crédito rural é, hodiernamente, o penhor rural.

\section{CONCLUSÃO}

O penhor rural é instituto amplamente utilizado em sede de crédito rural. Assim, somente é utilizado para garantir o pagamento de dívidas contraídas para o financiamento da atividade rural para com entidades públicas ou particulares especialmente vinculadas, raramente tendo outra utilização.

Dessa maneira, a fim de obter recursos para o desenvolvimento da atividade rural, agrícola ou pecuária, o agricultor ou pecuarista tem a opção de empenhar determinados bens, sem serem eles subtraídos temporariamente de seu patrimônio, o que no caso de bens com finalidade de produção agrária seria inconcebível, posto que o agricultor ou pecuarista levantaria o capital necessário a implementação da atividade rural, mas não teria como realizá-la, posto que sem os instrumentos necessários para tal fim.

No entanto, o presente artigo trouxe um esboço de uma outra possibilidade de utilização do penhor rural: como garantia nos contratos de arrendamento rural.

Não há disposição alguma no Estatuto da Terra que pudesse vedar tal utilização. Além disso, os pressupostos para sua utilização estariam satisfeitos, pois a obrigação principal estaria voltada à atividade agrária, os bens empenhados, 
igualmente, poderiam continuar na posse do empenhante-arrendatário, de modo a não subtrair-lhe os instrumentos necessários à sua produção. Em contrapartida, estaria o proprietário da terra munido do privilégio de receber seu crédito prioritariamente aos demais credores, em caso de inadimplemento e eventual insolvência do arrendatário.

Sendo assim, ambos os contratantes estariam satisfeitos, uma vez que diante da exigibilidade de garantia pelo arrendador, ofereceria o arrendatário os bens que utiliza na produção rural, sem ser privado de utilizá-los; e, da mesma maneira, em caso de inadimplemento do arrendatário no pagamento do aluguel, teria o arrendador a possibilidade de obter o valor não-pago através da venda judicial ou amigável, esta última se prevista no contrato, do bem empenhado.

\section{BIBLIOGRAFIA}

BARROS, Wellington Pacheco. Curso de Direito Agrário. 3. ed., vol. I. Ed. Livraria do Advogado, Porto Alegre, 1998.

COELHO, José Fernando Lutz. Contratos Agrários de Arrendamento e Parceria Rural no Mercosul. Ed. Juruá, Curitiba, 2002.

GOMES, Orlando. Direitos Reais. 14. ed. atual. por Humberto Theodoro Júnior. Ed. Revista Forense, Rio de Janeiro, 1999.

PONTES DE MIRANDA, Franscico Cavalcanti. Tratado de Direito Privado. 3. ed. Tomo XX. Ed. Revista dos Tribunais, Rio de Janeiro, 1983.

MONTEIRO, Washington de Barros. Curso de Direito Civil - Direito das Coisas. 37. ed. rev. e atual. por Carlos Alberto Dabus Maluf. Ed. Saraiva, São Paulo, 2003.

NASCIMENTO, Tupinambá Miguel Castro do. Penhor e Anticrese. Ed. Aide, Rio de Janeiro, 1986.

OPTIZ, Oswaldo \& Silvia C. B. Contratos no Direito Agrário. 5. ed. Ed. Síntese, Porto Alegre, 2000.

PEREIRA, Caio Mário da Silva. Instituições de Direito Civil. 18. ed. rev. e atual. por Carlos Edison do Rego Monteiro Filho, vol. IV. Ed. Forense, Rio de Janeiro, 2003.

RIZZARDO, Arnaldo. Direito das Coisas. Ed. Forense, Rio de Janeiro, 2004. 
SANTOS, J.M. de Carvalho. Código Civil Interpretado. Direito das Coisas. 12. ed. vol. X. Ed. Freitas Bastos, Rio de Janeiro, 1982. 